Jativa, Vol. 2, No. 2, July - December 2010, pp. 76-82 ISSN 0975-332X | https://doi.org/10.12726/tjp.4.7

Tattua

JOURNAL OF PHILOSOPHY

\title{
WHITEHEAD AND INTERCULTURAL PHILOSOPHY
}

\author{
Maja Milcinski, Ph. D
}

Whitehead reminds us once more of the plural approach of the European tradition at the end of the $18^{\text {th }}$ century, one that even today we can hardly imagine. Only by the end of the $18^{\text {th }}$ cenluny was philosophy understood as a European or "western" undertaking which was supposed to originate in Greece. Such a pluralistic approach was discontinued due to the narrative approach of European philosophy that opened the way to Hegel. Paradoxically, in his philosophy the so cherished universality of rationality has started to manifest itself only locally (in Greece, for instance). With Whitehead it has changed again and I will try to show the inspiring parts of Process and Reality, Religion in the Making and Science and the Modern World for the intercultural philosophy.

In Religion in the Making Whitehead reflects on India and China in his thesis on world-consciousness:

In India and China the growth of world-consciousness was different in its details, but in its essence depended on the same factors. Individuals were disengaged from their immediate social setting in ways, which promoted thought. ${ }^{1}$

Today if would be impossible to doubt that reality can be described in a multifude of ways. Also, the fact that we disagree on something can be interpreted as the

01. A. N. Whitehead. Refigion in the Making. New York: The New American Library, 1974, 39. 
highest virtue and not a disaster, since it is the way by which various important aspects of thought and emotions can be expressed. This is not due to the discovery of a kind of new dimension, but rather to the principle of diversity which originates in Greek, as well as in Indian and Chinese traditions. The epochs of such transitions, however, are often marked by great hopes and enthusiasms that provide the feeling of a certain all-embracing understanding of everything happening around us. We have to be aware, however, of the fact that the validity, incontestability and credibility of certain ideas is not present in the material text itself, but is rather the product of the closeness and familiarity with the ideas. Certain words and texts carry the meanings for us, since we became part and heirs of two thousand years of uninterrupted tradition. The closeness and knowledge of certain ideas does not necessary mean that these ideas (and not any others) are also true. In this case, as well, we have to be critical towards cultural prejudices and should not close the ways to different traditions.

In Process and Reality Whitehead pointed of the relation between general good and the individual interest, an idea that is very close to the Indra's web and Leibniz's idea of interrelatedness. Not only does Leibniz and his philosophy represent a great contribution to the European philosopher to study and approach Asian philosophical traditions, his disciple Christian Wolff (1679-1754) has pointed to similar components of seemingly different worlds, which sometimes connect us in quife paradoxical ways. This was the time when the Europeans were confronted in Asia with something very similar to the undertakings they knew under the name of "philosophy" and therefore righteously believed that it also was "philosophy". Wolff, who in 1721 held a lecture on natural theology of the Chinese, stressed the fact that Chinese were able to come to the moral truth without revelation. It turned out that the arguments against the so-called Asian philosophies and Confucianism in particular were intended to define them as atheistic, yet not imply that they did not meet the standards of "philosophy". Therefore Wolff, because of his interest in the Chinese tradition, was accused of atheism and fired from his university post in Halle and in 1723 forced to flee from Prussia under fear of decapitation - just because Chinese philosophy left some space for the thought that moral attitude was possible even without faith in an anthropomorphic God.

Morality of outlook is inseparably conjoined with generality of outlook. The antithesis between the general good and the individual interest can be abolished only when the individual is such that its interest is the general good, thus exemplifying the loss of the minor intensities in order to find them agoin with fines composition in a wider sweep of interest. ${ }^{2}$

02. A. N. Whitehead. Process and Reality. New York: The Free Press, 1978, 15. 
What challenge can this be for us, in the third millenium? In the Chinese tradition there is the obvious absence of any myth of creation, but rather a basic premise of reality that all phenomena and things are organically connected. There is no creator (God) who would act from the outside. Instead the creation grows from inside. There is a complete oneness identity between the creative and the created, an organic, unbroken process of transformation. In Buddhism, as well as in some other Asian traditions, the principles of ecology, the mutual dependence and interrelatedness of phenomena, are central. These traditions do not build on analysis, classification and isolation, which divide everything into groups that can then be easily intellectually and technologically manipulated, but rather in the spirit of cosmic ecology develops the view of humans, nature and their relationship. That view of existence that the theory of the Indra net provides, the worldview that does not build on any idea of initial time, creator or purpose, is very close to Leibniz's theory. In this worldview there is no hierarchy with God the creator at the top and the sequence of species below (from humans, animals, plants and stones at the bottom). There is also no room for the idea of a special position of humans who would own the cosmos for their own intentions in what is called human history, which is basically how history of the universe is understood. This would from the Buddhist point of view be understood as a specieistic delirium, not in the medical but in Hume's sense of the word. ${ }^{3}$ There is no center - and if there is, it is evenywhere. This worldview presupposes that human beings can develop solely as very fortunate and very rare phenomena of reincarnation, but this does not excuse or condition the argument that the human being is the measure of everything.

\section{In Science and the Modern World Whitehead described religion as}

The vision of something which stands beyond, behind and within the passing flux of immediate things; something which is real, and yet waiting to be realized; something which is a remote possibility, and yet the greatest of present facts; something which gives meaning to all that passes and yet eludes apprehension; something whose possession is the ultimate good, and yet beyond all reach; something which is the ultimate ideal, and yet the hopeless quest: ${ }^{4}$

By this definition we can acknowledge that Buddhism, as well, has all the characteristics of religion, although Buddha, after his enlightenment, taught the path to liberation mainly as a philosopher and not so much as a religious thinker. Everything that he taught was based on the natural order of things, as they can be perceived by our ordinary mind. Before that, however, we have to transcend and

03. D. Hume. A Treotise of Human Nature. Oxford: Clarendon Press, 1978, 269.

04. A. N. Whitehead. Science ond the Modern World. New York: The Free Press, 1966, 191-192. 
eliminate all the disturbing factors and the misleading forces. He did not learn anything revelational or suprahuman, there was also no mention of any absolute, superior being or any mystical elements. He was just mentioning two levels of truth: conventional truth and the absolute, supreme truth. The first one is representing the relative order of things, the one that appears to our empirical and rational mechanisms, or how we are able to perceive them. The second, however, represents the absolute order, which transcends the first one by giving the phenomena their place in the absolute and holistic order of things. This transcendence means that Buddha was able to perceive the things as they are and as can be perceived by ordinary beings. This is the distinction between the simple discriminatory knowledge (viiñôna) and undiscriminatory, penetrative wisdom (praiñâ). Buddha pointed in his doctrine to the harmonious structure of the world which transcends human sagacity of any kind.

Buddha himself had to decide between two paths: the conqueror of the world (chakravartin) or the enlightened one (Buddha). He chose the second one: the path of life acceptance with certain critical introspection and cleansing processes which helped him in eliminating external obstacles and in nurturing empathy and the ability to live through the dilemmas and crises of other human beings. This was also the motto of Russian novelist and poet Boris Pasternak who observed that we are just guests in this world, voyagers between two stations: birth and death. In this short time, which we spend on the Earth we have to come clear with our relationship to existence and our position in this universe. Otherwise life has no meaning. This means, however, the awakening of our spiritual life, religion, not as a Church dogma, but rather as an inner experience of life. The human being is born for life not for getting ready for life. Life itself, this phenomenon of life, the giff of life - all this is so movingly serious! ${ }^{5}$

With such seriousness we ought to ask ourselves if the notion of religion is satisfactorily covered by the idea of an anthropomorphic God, mythology and rituals, which does not offer space for meditation and expels the real seekers as heretics and therefore argue for Whitehead's definition of religion. This question should be even more seriously asked in the environments where the majority of inhabitants are formally catholic, where religion is understood as Church - the institution, which has its religious objects everywhere throughout the land. In such situations we ought to remind ourselves that religion cannot be equated with Church - as it has been and is practiced in the orthodox Catholicism - and that the moral sense cannot be codified to exhaustion. Due to the fact that religion deals with the overall sense of human existence, we have to be aware that what is finally recognized as

05. O. Ivinska. Leta s Pasternakom. Ljubljano: Mladinska knijga, 1983. 176. 
the absolute and final truth is also that infinite and inexhaustible source from which life and meaning springs, and which has been named (or even unnamed!) in different ways in different cultures. We also have to realize that there are ideological traps and undertakings that fry to give certain discourses an incontestable status and be critical towards certain ways of spiritual governance that try to mystify under the cover of demystifying.

Every tradition allows itself to think and move only in certain frames. Judeo-Christian and Muslim traditions have always built on the ideal of God as the basis of reality. Very few traditions, however, question their basic premises, although they are often logically inconsistent or even paradoxical. Such questioning is hindered by authoritarian doctrines, which themselves are only seldom placed under investigation; and if so, the critics ore either forgotten or else they become the initiators of a new fradition of thought, which builds on completely new premises. This was the case with Buddhism, which originates from the critical opproach of the previous philosophical and religious traditions. This is also the reason why the critical approach remained the central element of Buddhism, which was always polemical in dealing with religious matters.

Is the nature of religion satisfactorily defined in the realm of the Judeo-Christian heritage in the way as it treated the problems and oriented its believers or even named certain dimensions as thought and emotion objects? The interactions among cultures in the field of religion and philosophy are precious, even more so if we are able to feel them out of the context of the possible canonization or various attempts to govern traditional value systems, also the ones that do not recognize the ideas of development in the sense of accommodation to the so called western paradigm of development. What would possibly be the only "adequate" idea of the world, of humans' position in it and their experiences of it? Is this the one offered by the ancient Greek system of rationality on which the European spirit was founded also in regard to one's self-understanding and one's own relationship to other cultures (which were often just the negative images of the European one) and on which it based its dominance over other cultures? Such demonstration of differences in the nature and quality of mind and spirit would be very dangerous. What is the European or Judeo-Christian understanding of the world? Is Hegel with his hymn to the European spirit and its legitimization in regard to the ofhers (races, cultures, religions and philosophies) an exponent of these processes? With his elaborated rationalization of Eurocentrism as the basis of European colonialism he successfully degraded all so called primitive ones that did not yet participate in his Spirit. This can be seen as a case of dangerous reductionism and provincialism. He reduced the diversity of the world to a narrow frame of European rationality. Hegel's perceptions of different cultures are of course questionable and controversial, but 
we ought to remind ourselves also of thinkers like Nietzsche, Schopenhaver, Goethe, von Humboldt and Whitehead, who in their works initiated a dialogue with other cultures and religions and are therefore also important for the perception of our own tradition. The same was true for Leibniz, who was searching for universal characteristics, and by doing so included China in his philosophical-political discourse. Thus, he managed to transcend the narrow paradigms of the inner interpretation borders and the tools of perception and cognitive methods that were used in his time in Europe and which were later transcended by Whitehead. These are the notable exceptions that have with their tolerance acknowledged diverse axioms and rules or orientation in the world and life, which might be different from the narrow culfurally defined referential frame.

Excellent solutions, perceptions and ways of human life and giving sense to its existence, life and death have been found in various cultures and can, with their continuous influence, provide new sources of strength and inspiration, as well as important tools for revitalization of our own culture. It is true that when we talk about the future we can sometimes touch upon more poetical dimensions of human existence. Let the ways of achieving liberation, fulfillment and revitalization of human nature serve us as a starting point while examining our own folerance and openness for a sound dialogue, also when dealing with the concealed and culturally discriminated dimensions of ourselves. By doing this we should not try to devaluate or judge different discursive practices, but try to keep the distinction between soteriology and soterology ${ }^{6}$ in mind.

The soteriological feeling can be the final point of a successful meditative path and can be experienced when the ego is immersed in the self and when the ineffable experience of liberation and redemption is reached. The essence of such experience is the feeling that something has been granted to us and not that we have reached it with a logically discursive method and extreme efforts of reasoning. In such moments we are ready for an experience close to the one which Jesus Christ was trying to pass on to the people. The methods are transcended when they are grown from rough logic to subtle insight. The idea that such experiences have been mediated to humankind by Jesus Christ or Îshvara or any other God is secondary. Pure philosophies can also quickly degrade into various religious structures with a multitude of mythological supplements and rituals. The genuine soteriological experience is ineffable. In the spirit of Daoism it could be put into relation with the inner source of permanent transformation and change of the entire universe, the way in which Dao works.

06. The Oxford English Dictionary (Oxford: Clorendon Press, 1989); and Websler's Encyclopedic Unabridged Dictionary of the English Language (New York: Portland House, 1989), 1359. The 1994 edition does not make this distinction anymore. 
When everyone in the world knows the beautiful as beautiful, ugliness comes into being;

When everyone knows the good, then the not good comes to be.

The mutual production of being and nonbeing, the mutual completion of difficult and easy, the mutual formation of long and short, the mutual filling of high and low, the mutual harmony of tone and voice, the mutual following of front and back - these are all constants.

Therefore the Sage dwells in nonactive affairs and practices the wordless teaching.

The ten thousand things arise, but he doesn't begin them;

He acts on their behalf, but he doesn't make them dependent;

He accomplishes his tasks, but he doesn't dwell on them;

It is only because he doesn't dwell on them that they therefore do not leave him.?

Daoism builds on the standpoint that differentiation between good, bad, life-death is questionable, since it presupposes duality and bipolarity which should be transcended. The consciousness of the unity and connectedness of everything provides the paradisiacal dimension, which is not an unattainable or remote ideal, but rather nurture of sacredness here and now. It is based on the awareness that each and every moment is unique and united with all the others. Dao is the modus of existence of five phases, operational qualities, which immerse in each other and of yin and yang. Life is the coming together of yin and yang, and death is their separation. The soteriological, liberational dimension in Daoism is also related to the surplus, to that which transcends the language and happens in the arena of meditation, where the thoughts disappear. That is the realm of the transrational, the field of pure truth which cannof be reached by language. Daoist cultivation of freedom presupposes the elimination of the ego which is the condition for the unification with the Dao, big nature. In this state we are no longer affected by any limitations, we live and are not separated from the environment. As part of nature, and not as individuals separated from it, we can no longer differentiate between inner and outer realm, the general good and the individual interest.

07. Lao-Tzu. Te-Tao Ching. Trans. R. Henricks. New York: Ballanline Books, 1989, 54. 